\title{
UK Analogue Mission Research: The Case for STEAM Education and Outreach
}

\author{
Alexander Owens \\ UK Analogue Mission (UKAM) \\ alex.owens@ukam.space \\ Dilan Kaplan \\ UK Analogue Mission (UKAM) \\ dilan.kaplan@ukam.space
}

\author{
Konstantin Chterev \\ UK Analogue Mission (UKAM) \\ konstantin.chterev@ukam.space \\ Thom Charlie Clark \\ UK Analogue Mission (UKAM) \\ thom.clark@ukam.space
}

With little access to practical opportunities within the space industry for UK students, we have founded the UK Analogue Mission (UKAM) to provide motivated students with the platform to develop their skills and knowledge for their future careers. We believe that by utilizing our network and expertise, we can use UK-led space analogue missions to connect students from various disciplines and elevate the potential of the next generation of students.

There is a rise in popularity and demand for analogue missions across the globe. Organizations in Austria and Israel [1][2] are using these initiatives to raise human spaceflight awareness to the public, as well as providing opportunities for students involving habitat design, experiments, and mission planning.

Our goal is to increase the UK's human spaceflight capabilities and collaborate on the global stage with our own British astronauts. The strength of this was demonstrated by Tim Peake and his Principia mission which invited hundreds of students to the Science Museum in London and spurred a new wave of interest into UK spaceflight activities. The UK Space Agency (UKSA) Space Environments and Human Spaceflight Strategy [3] was further evidence of this, where David Parker argued that the UK should be "exploiting the unique opportunities for growth which human spaceflight and associated research programs can offer". Analogue missions provide a valuable niche and enrich the desire to go to space.

Setting aside the importance this platform has for students, analogue missions simultaneously benefits technology demonstrations to raise Technology Readiness Level (TLR) in preparation for future space exploration. Exposing students to these demonstrations is a great way to stimulate inspiration to develop current and future innovations for the advancement of the space industry.

With this ever-evolving industry and the rapid acceleration of innovation and technology, analogue missions provide a rich platform for students, young professionals, and organizations to come together for unique collaboration opportunities. Utilizing resources and expertise across all disciplines, we will elevate the UK space industry onto the international playing field.

\section{Keywords - analogues, demonstrations, STEAM, students}

\section{INTRODUCTION}

Science, Technology, Engineering, Arts and Mathematics (otherwise known as STEAM) have seen a large rise in popularity over the last few years. With this, there has been an increase in the number of organizations dedicated to providing STEAM learning resources, outreach events, education programs and more to ensure the enthusiasm for these subjects does not waiver. That being said, there are still limited opportunities for students and young professionals to get involved in practical activities that contribute to research and development (R\&D) to drive innovation and technology.

One of the topics known to engage the general public is human spaceflight. Moving forward, this can be a strong tool used to help inspire the next generation of enthusiasts to follow an education, and consequently a career in STEAM subjects. Astronauts are generally thought to be the 'glamorous' part of space exploration and this is what the younger generations typically think of when they consider activities in space. Educators can use this passion as a starting point to teach the public about the other uses of space and the possibilities available to get involved in STEAM in general.

A way in which we can harness this passion for space education is analogue missions. An analogue mission is a situation, environment or event on Earth that replicates the conditions of outer space, or another celestial body. These can be used to test the performance of new technologies destined for other planets or put the human body through similar effects as living and working in off-world environments, helping us learn, practice and prepare for the future. Analogues also allow us to understand the organizational challenges involved when living in outer space. Astronauts in space and living on other worlds may seem like something that is not readily accessible to the general public, but by using analogue missions, we can demonstrate the technologies involved in human space exploration, here on Earth. 
The problem we address in this paper combines the need for more STEAM education activities, lack of practical opportunities for young people in innovative STEAM projects and the absence of a UK human spaceflight program. We present our solution to this as the UK Analogue Mission, a not-for-profit company founded in 2018 to address the gaps in the UK space industry and provide a platform for technological advancements in space technology.

\section{STEAM}

The number of people studying STEAM subjects in Higher Education in the UK has generally increased over the last few years. From the academic year 2013/2014 to 2017/2018, the number of students studying STEAM subjects per year has increased by nearly 73,000 as shown in figure 1 . This has been due to a rise in government initiatives and new organizations looking to promote career paths in technical disciplines.

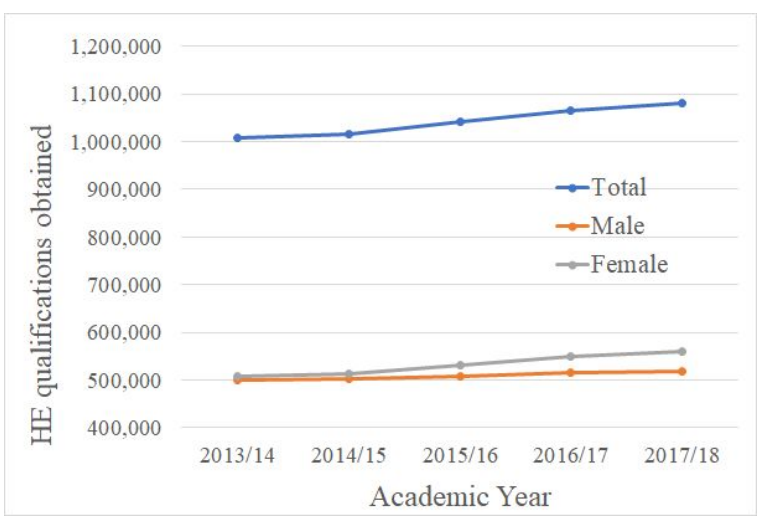

Figure 1 - Number of students in Higher Education Programs [4]

Despite this rise, it was reported in the Engineering UK 2018 report [5] that $61 \%$ of businesses in the UK are not confident that there will be enough highly skilled candidates to fill their job vacancies in the future. To aid in solving the problem of the increasing demand for these candidates, opportunities should be made more readily available to students, to participate in practical projects and to further their skills to complement academic knowledge. In the space sector, opportunities of this kind are particularly rare and occasionally not well advertised, as outlined in a paper presented at the SSEA 2018 [6]. This is something that must improve promptly for alignment with the government strategy laid out in 2017 [7]. One of the main focus points was the crucial role of education in narrowing skills gaps through driving skills, economic growth, and productivity. This was heavily welcomed by the engineering community.

Practical STEAM projects as an aid to the educational curriculum provide students with the opportunity to enhance their 'soft skills'. These projects can help teach creative problem solving, critical thinking, project management, team collaboration, and systems-level thinking. The kind of skills mentioned here are often difficult to demonstrate in a classroom environment, but competitions such as the
Spaceport America Cup [8], European Rover Challenge [9] and University Rover Challenge [10] provide excellent opportunities to put 'soft skills' to use along with educated knowledge. The drawback to these competitions for UK teams is that they are often held abroad and involve high costs to be competitive.

By increasing the number of practical STEAM opportunities available to young people; conducting outreach events to raise the awareness of these programs and communicating the advantages of getting involved, we can inspire the next generation to continue with their studies and begin to close the identified skills gap within the industry.

\section{Human Spaceflight in the UK}

To date, there have been six British-born people who have been into space, most notably Helen Sharman who flew on the Mir Space Station, Michael Foale, a NASA astronaut who participated in six spaceflights and Tim Peake who famously was the first British ESA astronaut.

Helen Sharman flew to the Mir Space Station in 1991 on the Soyuz TM-12 mission, as part of Project Juno, a joint Soviet Union-British mission funded by a host of British companies. She spent a total of eight days on-board performing mainly agricultural experiments. In the eight years following Helen's mission, she was self-employed as a Science communicator and was awarded the Order of St Michael and St George (CMG) in 2018 for her services to Science and Technology Educational Outreach.

Until recently, the UK government did not contribute funds to ESA's human spaceflight activities. In 2008, the UK Science Minister at the time gave impetus for the UK to change this and to have an astronaut 'icon', to inspire the next generation into studying technical subjects [11], which lead to Tim Peake flying to the International Space Station as part of the Principia mission in 2015. A report published by the UK Space Agency (UKSA) [12] measures the impact that Principia had and states that more than 33 million people engaged with the mission. A part of this included 34 educational projects delivered by UKSA which benefited from over $£ 3,000,000$ of funding and engaged nearly 3 million people. The Principia report also revealed that the awareness of the economic benefits of the space industry rose to $43 \%$ of the UK public.

The rise of the level of engagement and the amount of interest in space from Tim Peake's mission highlights the value of using human spaceflight as a centrepiece to enhance passion for space in the general public. To build on the enthusiasm generated by Principia, the UK should look to continue and increase the number of space educational activities by using Tim's mission and human spaceflight as a focal point, to teach and engage the public about the UK space program as a whole. 


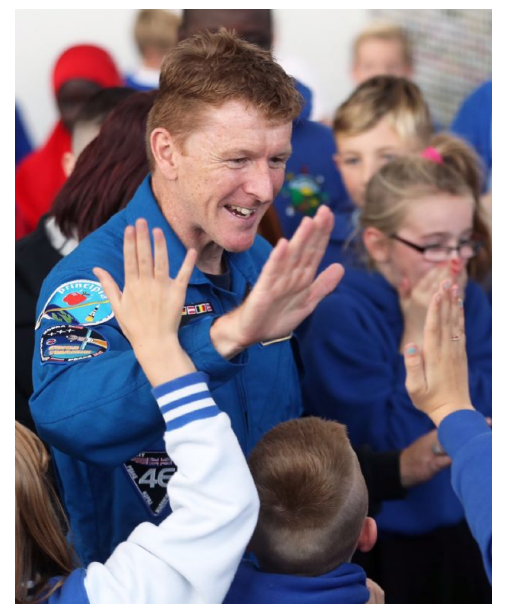

Tim Peake on his post-flight tour in 2015. Credit: UK Space Agency

The development of a UK human spaceflight program would be in line with the space environments and human spaceflight national strategy, published by the UK Space Agency in 2015 [13]. Highlighted goals of this strategy include utilizing space environments platforms, exploiting the public fascination for human spaceflight for the benefit of encouraging young people to enroll in STEAM subjects, and delivering science and technology for the advantage of terrestrial downstream applications. These aforementioned goals are very much aligned with those set out at UKAM and so the development of a UK human spaceflight program is something that we strongly advocate for. Alongside UKAM, there is already an active foundation in place to establish this with companies such as Blue Abyss [14], who have plans to develop a space extreme environment research, training and test centre, with the UK also having a strong presence in the research field of space medicine.

\section{Analogue Missions}

Analogue Missions are activities or projects carried out on Earth that aim to simulate conditions off-world. These can include but are not limited to: the Moon, Mars, and asteroids. These types of missions simulate environmental conditions similar to those on other celestial bodies, to test technology and overcome operational challenges.

Analogues vary in environmental conditions and research focus depending on the organization conducting the mission. For example, the "aquanauts" at NASA's underwater base "NEEMO" learn how to conduct experiments and perform in a "low-gravity" environment [15]. NEEMO analogue vision contrast from that of the Mars Society's Mars Desert Research Station (MDRS), which focuses on biological and geological studies, but also serves as a testbed for technological demonstrations including the "University Rover Challenge" $[10,16,17]$. This challenge looks to improve rover capabilities and tests their potential in performing teleoperated or autonomous tasks that may assist future astronauts in their work. There are also analogues that aim to be multi-disciplinary in their work, such as the Austrian Space Forum (OeWF) "AMADEE" missions, which undertake a wide array of research domains; this took place most recently in 2018, in Oman [18]. The OeWF has over 15 years of analogue experience, providing fields such as astrobiology and mission operations with valuable insights over the past decade. The OeWF have, and continue to undertake a multitude of public events, projects, and internships alongside their analogue missions, which all demonstrate how analogue missions can benefit STEAM education and outreach. For example, student teams from Oman and Austria were selected and trained for the AMADEE-18 mission, where they helped experiment definition and teleoperations, as well as conduct data analysis and presentation at future science workshops. Further, public engagement was achieved through live-streamed participation with several science centers in Austria and Oman. The mission social media campaign achieved a reach of millions on Twitter, as well as several thousand likes on Facebook, suggesting popularity and successful engagement [18].

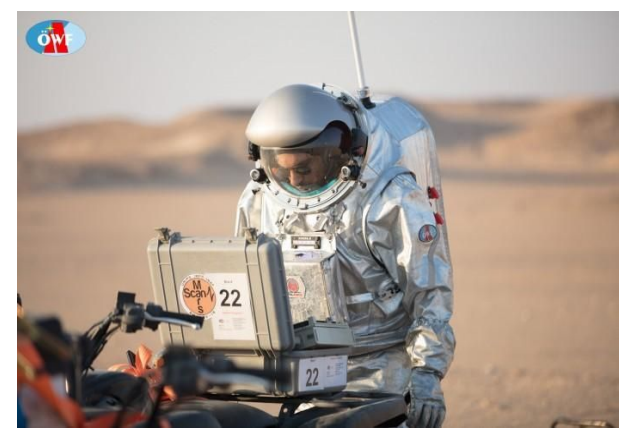

Austrian Space Forum (OeWF) AMADEE-18 mission. Credit: OeWF/Florian Voggeneder

Analogue missions are becoming increasingly popular; this has been demonstrated by "D-Mars" in Israel, who established themselves in 2017; they have since undergone several analogue missions to the benefit of both professionals and young students [19]. Such projects serve as strong educational facilitators for younger enthusiasts, but also provide researchers from varying disciplines to test their research and technology. With both "Old Space" and "New Space" players proposing missions to the Moon and Mars, such technology and operational challenges are necessary to be explored and understood on a deeper level. Examples of these missions include NASA's "Artemis" Program to the Moon, and SpaceX's goal of "enabling people to live on other planets" $[20,21]$. Analogue missions allow technological and operational testing needs to be met and researched in low-cost and relevant fidelity conditions and can be beneficial in:

- Assisting multidisciplinary research (including human factors, engineering, sciences) 
- Influencing new technologies and their application within society,

- Fostering international collaboration,

- Exploring the benefits of human and robotic exploration

- Inspiring the younger generation and the public. [22]

\section{Technology Development}

Analogue Missions present a unique opportunity for futureproofing, technology demonstration (TD) and research. They have the potential to demonstrate off-world human-machine interfaces with realistic, simulated circumstances. Stressful situations, confinement, interpersonal experience, and unfamiliar environments all have the ability to affect human performance and hence user-operated technologies.

TD is an important component of human spaceflight missions, with the Space Technology Mission Directorate and the Advanced Exploration Systems [23] [24] programs being run onboard the ISS. Technological Research and Development will undoubtedly be present in at least the first human missions to other celestial bodies, helping to pave the way for future technologies such as In-Situ Resource Utilization (ISRU) and Environmental Control and Life Support Systems (ECLSS), making it vital to have experience through Analogue Mission simulation. This also provides opportunities for collaboration or fund generation through companies, organizations or universities wishing to conduct relevant demonstrations or research, whilst potentially offering them publicity and exposure. In this context, TD is usually conducted through pre-determined experiments to test the capabilities of technologies and the effect of the human condition in their performance.

The type of technology that can be demonstrated during an analogue mission is dependent on the type of mission. This includes the mission concept and intended outcomes, the location of the mission and the analogue mission crew. The location is a crucial factor because it defines the compatibility of the environment with the technology i.e. whether the mission is designed for a Lunar or Mars simulation. The mission crew is another important factor to consider for the analysis of team structure, individual training, and experience. For example, a mission in which the participants are confined within their habitat dictates the usefulness of the testing that can be completed; there would also be vast differences in the technology applicable to a mission on a glacier, and a mission in the desert.

Some examples of the types of technology demonstrated from current analogue missions, such as AMADEE, MDRS, DMARS, and NEEMO [10, 15, 16, 17, 19, 25], include:

- Navigation Systems

- Geographical survey drones

- Biomedical sensors

- EVA suits

- ISRU or surveying rovers
- 3D printers

- Geological survey hardware

- Hydrological survey hardware

- Astrobiological/Biotechnology research payloads

- Volatile Organic Compound (VOC) sensing systems

- Habitats

- Mobility Vehicles

- Communication Systems

- Agricultural Technologies

These examples demonstrate the rationale for analogue missions as a testbed for any technology with off-world applications that can give benefit to or benefit from a human component.

Whilst the UK has developed and contributed to technologies within unmanned space exploration missions in recent years, such as ExoMars, Bepicolombo, and InSight, there is a lack of demonstration platforms involving a human component. There is an exception in the Airbus Stevenage Mars Yard - a testing ground for the ExoMars rover, but this remains reasonably exclusive and designed for the testing of autonomous systems. A UK-run analogue mission could provide a more accessible, diverse platform for TD, applicable to technologies designed with a human interface.

There is great potential for TD to provide STEAM outreach opportunities, by allowing students of various ages to provide technologies, ideas or experiments to a mission, as showcased by the OeWF with their Junior Explorers' Experiments [18]. These opportunities allow students to develop their 'soft skills' such as critical thinking, team-work, and problem-solving, and provide students in education with relevant, hands-on skills that can be carried forward into higher education or advance their careers.

\section{UK Analogue Mission}

At UKAM, we aim to be this platform for engaging students in STEAM education. Our goal is to first invite students from the various disciplines to work with our architects when building our habitat. The purpose of this is to highlight the requirement for specialists in different fields when building space habitats. UKAM has readily identified a lack of awareness within STEAM disciplines for the applicability of their knowledge within the space industry. In addition, UKAM has designed several mission competitions targeted at UK universities tailored to captivate students across all disciplines. With this in mind, UKAM is working hard to collaborate closely with a variety of universities not only through partnerships but also through utilizing the habitat for the purposes of attaining specific course credits when participating in missions and projects. The involvement of universities is essential in increasing student engagement as this is the frontline for student access, it is in this light that UKAM is offering tailor-made in-house lectures for STEAM subjects by utilizing our specialist network within the space industry. It is through our large array of networks that we hope 
to connect our students with the next stages of their future space careers.

\section{CONCLUSION}

The challenges that lie ahead in regard to STEAM education and involvement have been presented and we have highlighted the major role that human spaceflight and technology development can play in overcoming these challenges. As a solution to this, we have introduced the UK Analogue Mission (UKAM) which has the aim of simulating crewed spaceflight missions, providing practical opportunities in exciting and innovative projects, reigniting the passion for human spaceflight within the British public and promoting international and interdisciplinary STEAM collaboration.

\section{REFERENCES}

[1] Österreichisches Weltraum Forum (ÖWF). (2019). [online] Available at: https://oewf.org/ [Accessed 4 Apr. 2019].

[2] D-Mars (2019). [online] Available at: https://www.d-mars.org/ [Accessed 4 Apr. 2019].

[3] UK Space Agency (2019). National strategy: space environments and human spaceflight. [online] Available at: https://www.gov.uk/government/uploads/system/uploads/attach ment_data/file/649976/Space_Environments_and_Human_Spac eflight_Strategyv2.pdf [Accessed 4 Apr. 2019].

[4] HESA, "HE student enrolments by subject area and sex 2013/14 to 2017/18", 2019, Higher Education Student Statistics: UK, https://www.hesa.ac.uk/data-and-analysis/sb252/figure-14

[5] Engineering UK (2018). Engineering UK 2018: The state of engineering. [online] Available at: https://www.engineeringuk.com/media/1576/7444_enguk18_syn opsis_standalone_aw.pdf [Accessed 17 Jul. 2019].

[6] Robert Garner, Joseph Dudley. Removing Roadblocks from the UK space skills pipeline: A student and young professional Perspective. UK Students for the Exploration and Development of Space, SSEA 2018 Proceedings, SSEA-2018-84

[7] HM Government (2017). Industrial Strategy. Department for Business, Energy \& Industrial Strategy. Available at: https://assets.publishing.service.gov.uk/government/uploads/syst em/uploads/attachment_data/file/664563/industrial-strategy-whit e-paper-web-ready-version.pdf

[8] Spaceport America Cup. [online] Available at: http://www.spaceportamericacup.com/ [Accessed 17 Jul. 2019].

[9] European Rover Challenge. (2019). [online] Available at: http://roverchallenge.eu/ [Accessed 17 Jul. 2019].

[10] Mars Society. (2019). University Rover Challenge. [online] Available at: http://urc.marssociety.org/ [Accessed $17 \mathrm{Jul}$. 2019].

[11] Amos, J. (2019). Minister wants astronaut 'icon'. [online] BBC News - Science and Environment. Available at: http://news.bbc.co.uk/2/hi/science/nature/7662416.stm [Accessed 17 Jul. 2019].

[12] UK Space Agency. (2018). Impact Assessment: Principia Campaign. UK Gov. Available at: https://www.gov.uk/government/publications/impact-assessment -principia-campaign

[13] UK Space Agency. (2015). National strategy: space environments and human spaceflight. UK Gov. Available at: https://www.gov.uk/government/publications/national-strategy-s pace-environments-and-human-spaceflight

[14] Blue Abyss. [online]. Available at: http://blueabyss.uk/ [Accessed 18 Jul 2019]

[15] NASA. (2019). NASA Prepares for Future Moon Exploration with Undersea Crew. [online] Available at: https://www.nasa.gov/feature/nasa-prepares-for-future-moon-ex ploration-with-international-undersea-crew [Accessed 4 Jul. 2019].

[16] Meszyński, S. and Józefowicz, M. (2015). Analog Mars Rover Service as a Robotic Hardware and Team Building Platform. Aerospace Robotics II, pp.145-161.

[17] Post, M. and Lee, R. (2011). Lessons learned from the York University Rover Team (YURT) at the University Rover Challenge 2008-2009. Acta Astronautica, 68(7-8), pp.1343-1352.

[18] Austrian Space Forum (OeWF). (2019). AMADEE-18 Mars Analog Field Simulation, February 2018, Oman | OeWF. [online] Available at: https://oewf.org/en/portfolio/amadee-18/ [Accessed 4 Jul. 2019].

[19] From the Grapevine. (2019). Astronauts to simulate life on Mars in southern Israel biodome. [online] Available at: https://www.fromthegrapevine.com/videos/innovation/mars-mis sion-project-simulator-habitat-israel-astronaut [Accessed 4 Jul. 2019].

[20] Berger, E. (2019). NASA's full Artemis plan revealed: 37 launches and a lunar outpost. [online] Ars Technica. Available at:

https://arstechnica.com/science/2019/05/nasas-full-artemis-planrevealed-37-launches-and-a-lunar-outpost/ [Accessed 4 Jul. 2019].

[21] SpaceX. (2019). Company. [online] Available at: https://www.spacex.com/about [Accessed 4 Jul. 2019].

[22] Austrian Space Forum (OeWF). (2019). Why is Analog Research important?. [online] Available at: https://oewf.org/en/2016/07/why-analog-research/ [Accessed 4 Jul. 2019].

[23] STMD Technology Demonstrations Overview - [online] available at: https://www.nasa.gov/mission_pages/tdm/main/overview.html [accessed 6th August 2019]

[24] Advanced Exploration Systems Overview - [online] available at: https://www.nasa.gov/content/aes-overview [Accessed 6th August 2019]

[25] M. L. Reagan, B. A. Janoiko, J. E. Johnson, S. P. Chappel Ph.D, and A. F. Abercromby Ph.D, NASA's Analog Missions: Driving Exploration Through Innovative Testing, 2012, AIAA SPACE 2012 Conference \& Exposition, Pasadena, CA 